\title{
Experimental Investigation of the Deformability of Reinforced Concrete Slabs under Punching
}

\author{
Valery Filatov, ${ }^{1, *}$, and Eugene Bubnov ${ }^{1}$ \\ ${ }^{1}$ Samara State Technical University, Institute of Architecture and Civil Engineering, \\ Molodogvardeyskaya str. 194, 443001 Samara, Russia
}

\begin{abstract}
The results of investigations on the finite element models and test samples of flat reinforced concrete slabs of beamless frame under punching by columns of square and rectangular cross-section were shown in this paper. The research technique of reinforced concrete slabs deflections on finite element models at various loading schemes is given. Taking into consideration these results the optimum variant of load application has been chosen. Procedure and the tests results of experimental samples received, when studying of rigidity of fragments of flat reinforced concrete slabs by the action of punching force, are considered. A comparative analysis of the experimental values of the deflections of reinforced concrete slabs under punching by column of rectangular section, depending on the ratio of its sides, is completed. The research results allow to expand experimental data base as well as promote perfecting of modern positions in the theory of deformation of reinforced concrete.
\end{abstract}

\section{Research Deformability of Slabs on Finite Elements Models}

Numerical research on finite element models was carried out to define loading scheme when samples tests. It is known that deformations of slabs under uniformly distributed load and under concentrated forces is different. In the design of reinforced concrete structures is generally considered the action of uniformly distributed loads, while the test samples during the test load is applied in the form of concentrated forces. When testing linear construction (beams and columns) this distinction isn't so essential or can be compensated by a design procedure, however, for slab constructions, working in two directions, influence of the loading scheme can be considerable [1]. Numerical methods are the effective tool for the research of stress-strain condition of reinforced concrete constructions and are successfully applied by the authors [2-5].

Investigation was carried out on the finite element models developed for three test samples. The test samples made of heavy concrete represent a fragment of monolithic joint of a column of rectangular section with flat plate. The varied parameter was the ratio of the sides of the column cross-section. Testing of samples was supposed to be carried out in the test frame by the application of loading when reinforced concrete slab will be punching by

*Corresponding author: vb_filatov@mail.ru 
the column. The aim of the numerical research was to define such scheme of application of concentrated forces on the plate, at which displacements of slab points would best correspond to displacements of the same slab points under the action of uniformly distributed load.

Finite element models were developed in the LIRA-SAPR 2014 environment and represented a reinforced concrete flat plate (finite element - "shell") in the middle of which the column fragment (finite element - "rod") is located. Plate and column connection was modeled by the options "absolutely rigid body" which was set in plate nodes and "absolutely rigid element" which was set in rods (column). The sizes of "absolutely rigid body" varied and corresponded to column cross-section $-200 \times 200 \mathrm{~mm}, 200 \times 500 \mathrm{~mm}$ and $200 \times 800 \mathrm{~mm}$.

At the first investigation stage the plate of finite element models was loaded with the uniformly distributed load to reveal vertical slab displacements. At the second stage of slab loading was made by the concentrated forces on the sites provided by a construction of the test frame. In this case the position of loading points along external side of a slab varied (on two points of loading along each side). Position of loading points on a plate was chosen in such a way that vertical displacements of finite element nodes of a plate corresponded to vertical displacements of these nodes under uniformly distributed load. The fields of equal vertical slab displacements of finite element models received by numerical research results are presented in Fig. 1, 2.
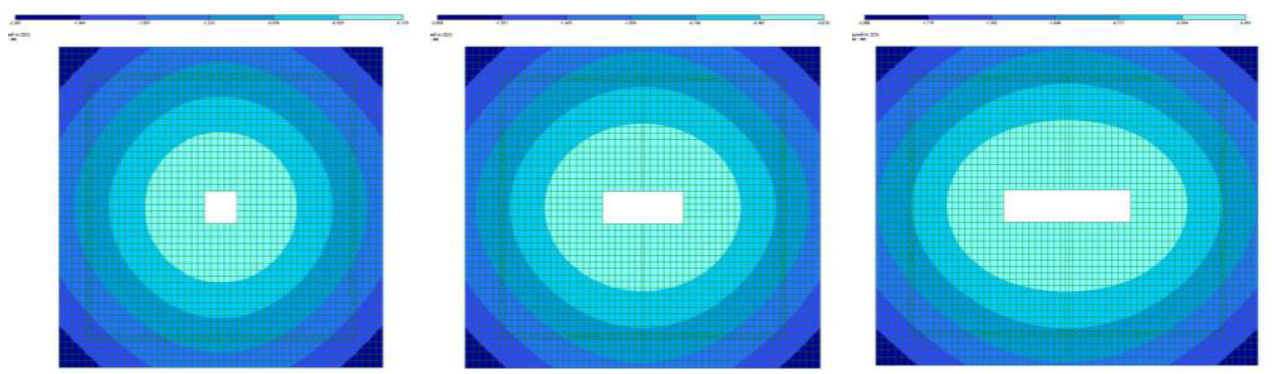

Fig. 1. Fields of equal vertical slab displacements under uniformly distributed loading.

Analysis of the results of finite element modeling shows that when a uniformly distributed load fields of equal vertical slab displacement for a square column are circumferentially and for a rectangular columns - an ellipse, the ratio of the major and minor axes of the ellipse varies with the ratio of the column cross-section side (Fig. 1). These features of plate deformation under load correspond to the theoretical assumptions about the nature of the plate deformation, presented in [6-8]. Presented in fig. 2 fields of equal vertical slab displacements under action of concentrated forces show that the chosen position of loading points on the plate provides satisfactory compliance of deformation slab nature at both schemes of loading.
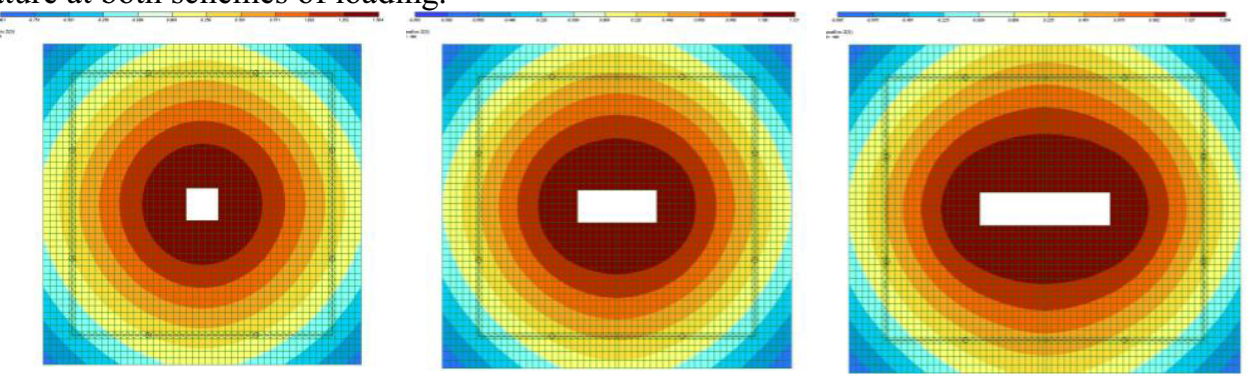

Fig. 2. Fields of equal vertical slab displacements under the action of concentrated forces. 


\section{Research Deformability of Slabs on Test Specimens}

Force resistance research of reinforced concrete structures under complex stress states (combined action of normal and shear forces, bending moments) has an empirical basis due to the work of concrete as a composite elastic-plastic material with discontinuities (cracks formation) $[9,10]$. Experimental investigation is performed to study character of the work construction to test the theoretical assumptions and further development of computational models and calculation methods [11-14]. The results of experimental and theoretical investigations of the strength and deformability of flat reinforced concrete slabs under punching, including rectangular columns, presented by the authors [1, 15-20].

Test samples investigated by the authors represented a fragment of reinforced concrete monolithic joint of rectangular cross-section column connection to a flat plate. The varied parameter was the ratio of the sides of the column cross-section. Three samples were tested:

- CMR-1 - column with square section size of $200 \mathrm{~mm}$ faces.

- CMR-2,5 - a column of rectangular section of the following size $-200 \times 500 \mathrm{~mm}$.

- CMR-4 - a column of rectangular section of the following size $-200 \times 800 \mathrm{~mm}$.

Slabs thickness of all test samples was $140 \mathrm{~mm}$. Reinforcing at the top (tensioned) side of a slab was carried out by reinforcing bars grade A500 with a diameter of $14 \mathrm{~mm}$ at 100 $\mathrm{mm}$ spacing, at lower (compressed) side reinforcing bars grade B500 with a diameter of 5 $\mathrm{mm}$ at $100 \mathrm{~mm}$ spacing is accepted. Transverse reinforcement in the slab was absent. Cube strength of the concrete was: for CMR-1 sample - $40 \mathrm{MPa}$, for samples of CMR-2.5 and CMR-4 - $30 \mathrm{MPa}$.

Test samples loading was carried out in a test frame. Point load was created by a hydraulic jack with the loading capacity of $1000 \mathrm{kN}$ and applied to the bottom edge of the column. Load on test samples slab was transmitted through four metal beams having two hinged points of support on the upper face of the plate. Beams were held by tie rods passing through the sleeves in the sample plate and fixed in the power floor with the help of the traverses. To transfer uniform pressure upon a plate surface to eight points all beams, tie rods and traverses were of one standard size.

Deflections of slab were measured by means of dial gauges as the difference in slab displacements at a given point and near the surface of the column. Arrangement schemes of dial gauges and load application points on the test samples slabs are presented in Fig. 3. Width of cracks opening on a slab surface was measured by means of microscope.
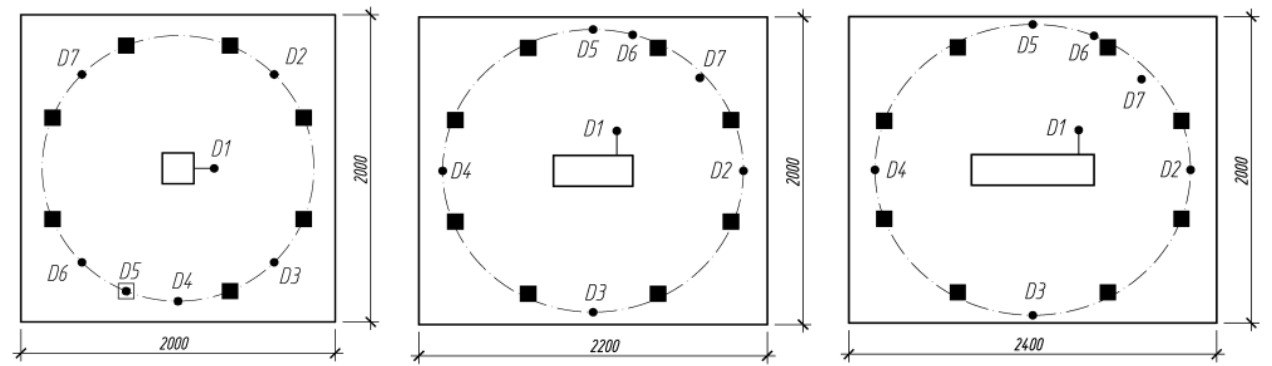

Fig. 3. Arrangement schemes of dial gauges and the points of application of concentrated forces.

The loading of the sample was carried out by steps of 5\% of the theoretical failure load. The exposure time of the sample under load at each step was 15 minutes. At each loading stage was made fixing values of strain gauges, indications of dial gauges, schemes of cracks formation and development. CMR-4 sample in the process of testing is shown in Fig. 4. 


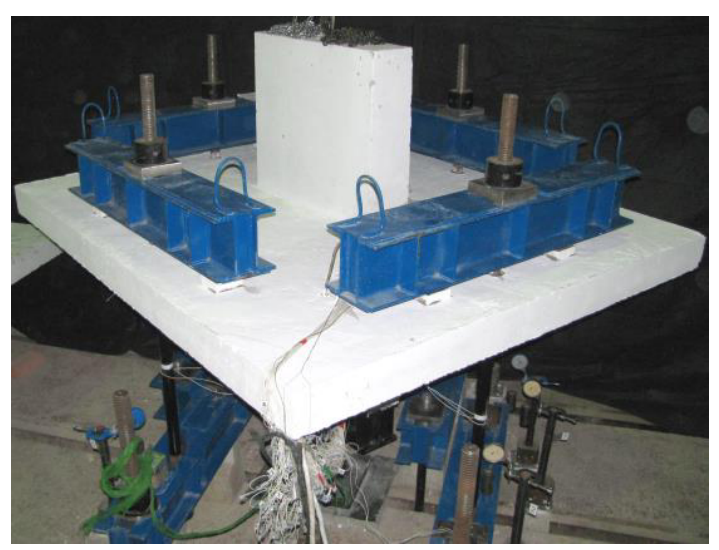

Fig. 4. Testing of sample CMR-4.

Failure of the samples was brittle due to punching plate by column. The values of failure loads reached $272 \mathrm{kN}, 281.3 \mathrm{kN}, 328.4 \mathrm{kN}$ for CMR-1, CMR-2.5 and CMR-4 samples, respectively.

The values of the plate deflections of sample CMR-1 before failure varied in the range $72.5-78 \mathrm{~mm}$, and the smallest deflection being noted on axis perpendicular to external edge of a slab (D4), and the greatest - on a diagonal axis of a slab (D7). Maximum divergence of values of deflections onto the opposite sides of a slab (D3 - D7 and D6 - D2) doesn't exceed $4 \%$ that allows to draw a conclusion about almost symmetric vertical slab displacements of CMR-1 sample in relation to a column in fixing points (Fig. 3). The values of deflections plates samples CMR-2.5 and CMR-4 before the failure exceeded deflections plate of the sample CMR-1 for $4-8 \%$ on the short side of the plate, and $8-11 \%$ on the long side. In general, the greatest deflections are noted on the long sides and diagonal axes of test samples slabs. Average values of deflections of test samples slabs depending on the level of loading are presented in Fig. 5.

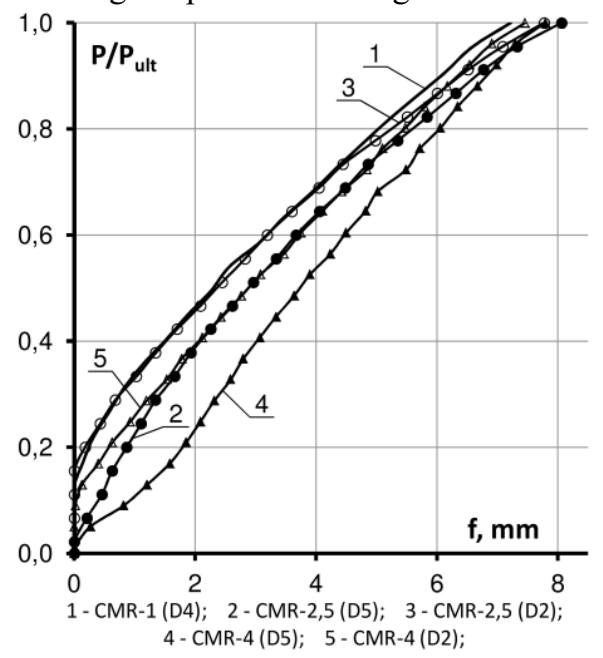

Fig. 5. Deflections of slabs CMR-1 $\div$ CMR-4 samples depending on loading level.

The offered testing technique reinforced concrete slabs on punching allows to model slabs work under uniformly distributed loading by the application of concentrated forces. The results of these studies indicate satisfactory convergence of the qualitative picture of the power resistance of reinforced concrete slabs to punching under the action of a 
uniformly distributed load and the concentrated forces. New experimental data on the strength and deformability of flat reinforced concrete slabs under punching by column of rectangular section, depending on the ratio of its sides, were obtained.

\section{References}

1. J. Sagaseta, L. Tassinari, M. Ruiz, A. Muttoni, Eng. Struct. 77, 17-33 (2014)

2. E.N. Kodysh, N.N. Trekin, D.N. Trekin, Concrete and reinforced concrete - glance at future: III All-Russian (II International) Conference on concrete and reinforced concrete, I, 69-75 (2014)

3. A.G. Tamrazyan, Industrial and civil engineering 7, 26-27 (2012)

4. N.I. Karpenko, B.S. Sokolov, O.V. Radaykin, Industrial and civil engineering 1, 28-30 (2013)

5. V.B. Filatov, A.A. Suvorov, Procedia Engineering 153, 144-150 (2016)

6. V.B. Filatov, Proceedings of the Samara scientific center of the Russian Academy of Sciences 14(4-5), 1322-1324 (2012)

7. V.B. Filatov, Bulletin of civil engineers 5(40), 80-84 (2013)

8. V.B. Filatov, E.P. Bubnov, A.K. Alekseev, M.A. Bruskov, Z.Sh. Galyautdinov, A.G. Proydin, Proceedings of the Samara scientific center of the Russian Academy of Sciences 16(4-3), 646-649 (2014)

9. V.I. Travush, V.I. Kolchunov, N.V. Klyueva, Industrial and civil engineering 3, 4-11 (2015)

10. V.I. Travush, S.G. Emel'yanov, V.I. Kolchunov, Industrial and civil engineering 7, 20 $27(2015)$

11. A.G. Tamrazyan,_Yu.N. Zvonov, Industrial and civil engineering 7, 24-28 (2016)

12. V.B. Filatov, Yu.V. Zhiltsov, Proceedings of the Samara scientific center of the Russian Academy of Sciences 14(4-5), 1325-1328 (2012)

13. V.B. Filatov, E.V. Blinkova, Industrial and civil engineering 3, 39-42 (2014)

14. V.B. Filatov, Concrete and reinforced concrete - glance at future: III All-Russian (II International) Conference on concrete and reinforced concrete I, 389-396 (2014)

15. N.N. Trekin, D.A. Pekin, Industrial and civil engineering 7, 17-20 (2014)

16. A.N. Bolgov, A.Z. Sokurov, Concrete and reinforced concrete - glance at future: III All-Russian (II International) Conference on concrete and reinforced concrete IV, 139149 (2014)

17. A.N. Bolgov, D.M. Yakimovich, Concrete and reinforced concrete - glance at future: III All-Russian (II International) Conference on concrete and reinforced concrete I, 224-233 (2014)

18. T. Susanto, H.K. Cheong, K.L. Kuang, J.Z. Geng, ACI Struct. J. 101(5), 678-687 (2004)

19. A. Muttoni, ACI Struct. J. 105(4), 440-450 (2008)

20. C.E. Broms, ACI Struct. J. 87(3), 292-304 (1990) 